\title{
Facilitating well-being and Performance through the Development of Strengths at Work: Results from an Intervention Program
}

\author{
Philippe Dubreuil $^{1}$ (D) . Jacques Forest ${ }^{2} \cdot$ Nicolas Gillet $^{3} \cdot$ Claude Fernet $^{1}$ • \\ Anaïs Thibault-Landry ${ }^{4} \cdot$ Laurence Crevier-Braud $^{4} \cdot$ Sarah Girouard $^{4}$
}

\begin{abstract}
The objective of the present pilot study was to test a strengths-based intervention program in the workplace and assess its impact on well-being, performance, harmonious passion, vitality and concentration of workers using a pretestposttest design. The intervention program was conducted on a sample of 78 participants
\end{abstract}

Philippe Dubreuil

philippe.dubreuil@uqtr.ca

Jacques Forest

forest.jacques@uqam.ca

Nicolas Gillet

nicolas.gillet@univ-tours.fr

Claude Fernet

claude.fernet@uqtr.ca

Anaïs Thibault-Landry

thibault-landry.anais@ courrier.uqam.ca

Laurence Crevier-Braud

crevier-braud.laurence@courrier.uqam.ca

Sarah Girouard

girouard.sarah.2@courrier.uqam.ca

1 Business School, Université du Québec à Trois-Rivières, 3351, boulevard des Forges, C.P. 500, Trois-Rivières, QC G9A 5H7, Canada

2 Department of Organization and Human Resources, ESG UQAM, C.P. 8888, Succ. Centre-Ville, Montréal, QC H3C 3P8, Canada

3 Department of Psychology, Université François-Rabelais de Tours, 3 rue des Tanneurs, 37041 Tours, Cedex 01, France

4 Department of Psychology, Université du Québec à Montréal (UQAM), C.P. 8888, Succ. Centre-Ville, Montréal, QC H3C 3P8, Canada 
working in a physical readaptation center and comprised three main steps: (1) Discovery, (2) Integration and (3) Action. Results from a series of paired sample t-tests revealed increases in participants' strengths use and well-being after the intervention. However, no difference was found regarding work performance, harmonious passion, vitality and concentration. Further analyses revealed that participants who reported high increases in strengths use also showed significant increases in harmonious passion and work performance. Theoretical and practical implications are discussed.

Keywords Strengths $\cdot$ Work $\cdot$ Well-being $\cdot$ Performance $\cdot$ Positive psychology

\section{Introduction}

For several decades of its recent history (e.g., Koch and Leary 1985), psychology mainly focused its energy in researching and knowing how it is possible and feasible to alleviate problems, healing and fixing harm in different spheres of life, be it work, family, relationships and personal life. At the dawn of the twenty-first century, several researchers identified the urgent necessity to simultaneously diminish suffering and increase flourishing, happiness, well-being and meaning. This innovative new field, which has been termed positive psychology, aims at increasing positive emotions, attitudes, behaviors and institutions (e.g., Csikszentmihalyi and Csikzsentmihalyi 2006; Linley and Joseph 2004; Lopez and Snyder 2009; Seligman and Csikszentmihalyi 2000; Snyder and Lopez 2002). It is thus a multi-level (e.g., individual, group, organization, society) and multi-domain (e.g., personal life, leisure, work) perspective which aims at concurrently increasing optimal functioning and diminishing ill-being. The research and interventions of positive psychology has also been found to be useful and meaningful in the work domain (e.g., Cameron et al. 2003; Linley, Harrington, \& Garcea, 2010) where we spend more than half our waking life. One chief way of increasing the positive and reducing the negative experiences at work is the identification and use of personal strengths (e.g., Peterson and Park 2006) and it is precisely the topic of the present article where we did a strengths' based intervention with a working adults population in a real-life setting.

\section{The Strengths Approach}

One of the main pillars of positive psychology is the strengths approach. According to this approach, each individual naturally possess a series of strengths, and personal investment in the identification, use and development of these strengths can foster positive outcomes such as well-being, performance, optimal functioning and fulfillment (Clifton and Harter 2003; Dubreuil et al. 2014; Forest et al. 2012; Linley and Harrington 2006; Peterson and Seligman 2004). In the last decade, various conceptualizations of strengths have been developed, which slightly differ in their definition, classification and measurement.

A first conceptualization of strengths was developed by Donald Clifton and his research team at the Gallup Organization. According to these authors, strengths can be defined as "the ability to provide consistent, near-perfect performance in an activity" and are produced through the refinement of talents with knowledge and skills (Hodges and Clifton 2004, p. 257). As such, talents are defined as "naturally recurring patterns of thought, feeling, or 
behavior that can be productively applied" (Hodges and Clifton 2004, p. 257). Based on this conceptualization of strengths and extensive research on talents conducted in the workplace, the Gallup Organization developed a classification of 34 themes of talents, along with the Clifton Strengthsfinder ${ }^{\circledR}$ (Asplund et al. 2007), an instrument designed to help individuals identify their main themes of talents and develop them into strengths.

A second conceptualization of strengths was developed by Peterson and Seligman (2004) in the early years of positive psychology. These authors developed the character strengths and virtues classification, which comprises 24 strengths categorized under six broad virtues, on the basis of a global review of strengths and virtues that consistently emerged across history and culture (Dahlsgaard et al. 2005; Peterson and Seligman 2004). This conceptualization was created in order to provide the emerging field of positive psychology with a common vocabulary and a framework for future research and interventions. According to Peterson and Seligman (2004), strengths represent "the psychological ingredients - processes or mechanisms - that define the virtues. Said another way, they are distinguishable routes to displaying one or another of the virtues" (Peterson and Seligman 2004, p.13). This classification also led to the development of the Values in Action (VIA) Inventory of Strengths Survey (Peterson and Seligman 2004), an instrument designed to help individuals identify their main character strengths.

A third conceptualization of strengths was developed by Linley (2008) and his research team at the Centre for Applied Positive Psychology (CAPP). According to these authors, strengths can be defined as "a pre-existing capacity for a particular way of behaving, thinking, or feeling that is authentic and energizing to the user, and enables optimal functioning, development and performance" (Linley 2008, p.9). Based on this definition and their experience in positive psychology interventions, the CAPP team developed their own classification of 60 strengths (Linley, Willars, \& Biswas-Diener, 2010) as well as the Realise2® (Linley 2009), an instrument that not only informs about individual strengths, but also indicates their relative levels of use and contribution to performance.

\section{Strengths, well-Being and Performance}

Research conducted in different settings has consistently shown that strengths use and development can increase well-being and performance. In the general population, Seligman et al. (2005) first demonstrated that strengths identification and development could have a positive and lasting effect on well-being. These results were supported by various studies linking strengths use to well-being (Govindji and Linley 2007; Park et al. 2004; Proyer et al. 2015; Rust et al. 2009; Wood et al. 2011) and confirmed in different replication studies (Gander et al. 2013; Mitchell et al. 2009; Mongrain and Anselmo-Matthews 2012). In educational settings, research revealed that strengths knowledge, use and development helped foster students' well-being and academic achievement (Duan et al. 2014; Park and Peterson 2008; Proctor et al. 2011; Quinlan et al. 2015; Seligman et al. 2009). In the workplace, research conducted on strengths use and development yielded similar results, with increases in employee well-being, engagement and job satisfaction (Forest et al. 2012; Harzer and Ruch 2012, 2013; Littman-Ovadia and Steger 2010; Peterson et al. 2010), as well as work performance (Asplund and Blacksmith 2012; Clifton and Harter 2003; Dubreuil et al. 2014; Harzer and Ruch 2014; Hodges and Asplund 2010; Kong and Ho 2015). 


\section{Strengths Use and Possible Underlying Processes}

Scholars and practitioners in the field of positive psychology generally agree on the idea that strengths use involves three types of psychological processes that might be responsible for these positive effects on well-being and performance: authenticity, vitality and flow (absorption). According to Linley (2008), people experience deep feelings of authenticity when they use their strengths - they feel like they are being themselves and that they follow their own directions and preferences in life. As well, their levels of energy, aliveness and vitality rise and they can experience episodes of flow. Peterson and Seligman (2004, p.18) describe similar processes in their list of criteria for strengths, stating: "a sense of ownership and authenticity ('this is the real me') vis-à-vis the strength, [and] invigoration rather than exhaustion while using the strength". In their work on strengths, Duckworth, Steen, and Seligman (2005, p.635) further add that "the wise deployment of strengths and talents leads to more engagement, absorption, and flow". In the same way, Buckingham (2007) describes in his SIGN model (Success, Instinct, Growth, Needs) that hallmarks of strengths are feelings of authenticity, excitement and "growth" (a state of deep concentration similar to flow), while Hodges and Clifton (2004, p. 258) refer to "spontaneous reactions" and feelings of "yearnings" towards activities involving strengths.

In the last decade, research on strengths has confirmed that these processes could indeed be involved in the relation between strengths use, well-being and performance. First, strengths use and development has been shown to increase harmonious passion (Forest et al. 2012), a concept closely related to authenticity which can be defined as a strong inclination towards an activity that people like, find important, invest significant time and energy in, and internalize in an autonomous way in their identity (Vallerand et al. 2014). Harmonious passion has in turn been associated to well-being (Forest et al. 2012; Forest et al. 2011; Philippe et al. 2009) and performance in different settings, such as work (Astakhova and Porter 2015; Ho et al. 2011), sports (Li 2010; Vallerand et al. 2008) and arts (Bonneville-Roussy et al. 2011; Vallerand et al. 2007). Similarly, significant relations have been found between strengths use and subjective vitality (Forest et al. 2012; Govindji and Linley 2007; Wood et al. 2011), while subjective vitality has been associated with well-being (Ryan and Frederick 1997) and work performance (Carmeli et al. 2009; Salanova et al. 2005). Likewise, strengths have also been shown to predict flow and absorption through the engaged life orientation to happiness (Buschor et al. 2013; Peterson et al. 2007), while flow has been associated to well-being (Fritz and Avsec 2007; Wanner et al. 2006) and performance at work (Demerouti 2006; Eisenberger et al. 2005; Kuo and Ho 2010), in sports (Bakker et al. 2011; Schuler and Brunner 2009; Stavrou et al. 2007) and academic settings (Engeser and Rheinberg 2008). More recently, research has further confirmed the plausibility of this general model, as strengths use was associated with work performance through the pathways of harmonious passion, subjective vitality and concentration (Dubreuil et al. 2014).

\section{The Present Research}

After an initial period in which positive psychology established its roots and foundations, conducting fundamental research, developing key concepts and organizing its structure (Csikszentmihalyi and Nakamura 2011; Linley et al. 2006; Peterson and Seligman 2004; Seligman and Csikszentmihalyi 2000), it is now entering a second 
phase in its evolution where it gradually expands into an applied science. As such, researchers and practitioners now actively call for a shift towards applied and more pragmatic research, especially in organizational settings, in order to pursue the development of the field, provide practitioners with empirically validated tools and methods, and further demonstrate the value of positive psychology among the public as well as the scientific community (Asplund and Blacksmith 2012; Biswas-Diener et al. 2011a; Csikszentmihalyi and Nakamura 2011; Kashdan and Steger 2011; Linley et al. 2011; Quinlan et al. 2012; Spreitzer and Cameron 2012).

The strengths approach, which is central to positive psychology, naturally follows the same direction. Until now, only a small number of studies have proposed and tested strengths-based interventions (Forest et al. 2012; Gander et al. 2013; Mitchell et al. 2009; Proctor et al. 2011; Rashid 2015; Rust et al. 2009; Seligman et al. 2005). More specifically in the workplace, while many studies reported positive associations between strengths, well-being (Forest et al. 2012; Harzer and Ruch 2012, 2013; LittmanOvadia and Steger 2010; Peterson et al. 2010) and work performance (Asplund and Blacksmith 2012; Clifton and Harter 2003; Dubreuil et al. 2014; Harzer and Ruch 2014; Hodges and Asplund 2010; Kong and Ho 2015), only a few proposed and tested strengths development interventions (Clifton and Harter 2003; Forest et al. 2012; Hodges and Asplund 2010) and to our knowledge, only two precisely described the protocol used in their intervention (Forest et al. 2012; Harzer and Ruch 2015).

In order to address these issues, we developed a strength-based intervention that could be delivered to individuals in the workplace and measured its effects on wellbeing and work performance, but also on harmonious passion, subjective vitality and concentration (a core component of the immediate experience of flow; Kawabata and Mallett 2011; Nakamura and Csikszentmihalyi 2002; Straume 2008). The intervention was based on the recommendations found in previous work conducted by BiswasDiener (2010), Biswas-Diener et al. (2011b), Buckingham (2007), Clifton and Harter (2003), Kaiser and Overfield (2011), Linley (2008), Linley, Willars, and Biswas-Diener (2010) and Seligman et al. (2005), and involved three general steps: (1) Discovery, (2) Integration and (3) Action. Broadly stated, in the discovery phase, participants were invited to identify their strengths using a strengths assessment tool. In the integration phase, participants were invited to reflect and discuss about their strengths with their peers. In the action phase, participants were invited to think about ways they could better use their strengths at work and discuss these opportunities with their colleagues.

\section{Objectives and Hypotheses}

Thus, the objective of the present study was to test the effectiveness of this specific strengths-based intervention program and assess its impact on well-being, performance, harmonious passion, vitality and concentration of workers. Based on the above theoretical rationale and empirical literature, the following hypotheses were proposed: after the intervention, there will be an increase in participants' (1) strengths knowledge, (2) strengths use, (3) well-being, (4) work performance, (5) harmonious passion, (6) subjective vitality and (7) concentration. 


\section{Method}

\section{Participants}

Participants were French-speaking employees from the health care sector working in a physical rehabilitation center in the province of Québec, Canada. Participants were recruited with the help of the human resources (HR) department of the institution. More specifically, the HR department offered employees to participate in a publicly funded research project on strengths. Participation was voluntary and the intervention was done on-site, during paid work hours, for those who accepted to participate in the project. From the 157 participants initially recruited at time 1 , a total of 78 participants completed both questionnaires at time 1 and time 2 (53\% completion rate). In this final sample of 78 participants (93\% women, which is representative of the workforce in the healthcare sector in this establishment), $21 \%$ were less than 30 years old, $48 \%$ between 30 and 45 years old, $26 \%$ between 46 and 55 years old and $5 \%$ were 56 years or older. Most participants had a technical college degree (57\%), while others had either a bachelor's degree (32\%) or a high school diploma (11\%). Regarding job tenure, $26 \%$ cumulated less than 5 years of experience with their current employer, $19 \%$ between 5 and 9 years, $22 \%$ between 10 and 14 years and $33 \% 15$ years or more. To rule out potential selection bias, we examined whether participants who completed both questionnaires (time 1 and time 2) were equivalent to those who completed the questionnaire at time 1 only. A series of independent t-tests and chi square tests indicated that the two samples did not differ significantly on background variables (age $[t(146)=-1.27, p>0.05]$, gender $\left[\chi^{2}(1)=0.95, p>0.05\right]$, education $\left[\chi^{2}(6)=11.18\right.$, $p>0.05]$, job tenure $[t(155)=-0.80, p>0.05]$ ) as well as on study variables (strengths knowledge $[t(155)=0.14, p>0.05]$, strengths use $[t(155)=-1.06, p>0.05]$, well-being $[t(155)=-1.31, p>0.05]$, work performance $[t(155)=0.16, p>0.05]$, harmonious passion $[t(150.64)=0.63, p>0.05]$, subjective vitality $[t(155)=-1.12, p>0.05]$, concentration $[F(152.14)=-1.93, p>0.05])$.

\section{Procedure}

The procedure involved a pre-test measurement, an intervention program and a posttest measurement. First, all participants received an email which contained a brief description of the project, an agreement form presenting in detail the aims and scope of the study, and a link referring to an online questionnaire. The agreement form was duplicated as the first part of the questionnaire and all participants had to confirm their agreement with the terms and conditions of research before they could proceed. Participants then completed the questionnaire (time 1), which asked them to report their levels on the studied variables. After completion of the questionnaire, they were instructed to proceed with the first step of the intervention program.

The intervention program comprised three steps: discovery, integration and action. The first step (discovery) consisted in the identification of participants' strengths with a strengths assessment tool (in our case, the VIA-Survey; Peterson and Seligman 2004), followed by the completion of a short questionnaire asking participants to further reflect on their results (e.g., "What do you think about your results? Does it confirm in some way what you already knew about yourself? Are you surprised in any way? Why?"). The purpose of these questions was to encourage a deeper consideration of the results 
and to act as a primer for the next phase. The second step (integration) consisted in a group meeting with participants two weeks later. In this group meeting, participants were asked by a facilitator to individually answer different questions relating to their strengths in the past, present and future (e.g., "Please take some time to think back about something you did that makes you particularly proud. It can be a decision you took recently, a personal accomplishment, something you decided to stand up for, etc. Which strengths were involved in this situation?; What kind of compliments do you usually receive at work? To which strengths does it refer?; In what circumstances would you say that you are 'at your best' at work? Which strengths are involved in these situations?"). These questions were designed to help participants better understand the nature of their strengths, how they translate into their daily lives and how they contribute to their success at work. Participants were then invited to discuss in small groups about their answers. This sharing process further contributed to the validation, acknowledgement and endorsement of strengths. After a brief pause $(20 \mathrm{~min})$, the group meeting continued with the third step (action). In this step, participants were asked by the facilitator to individually answer different questions relating to strengths development in the workplace (e.g., "Are there any strengths that remain underused in your work? If so, what can you do to change this situation and put them in action?; What can you do to let your colleagues and/or supervisor know about your strengths?; Could some strengths be used to counterbalance your weaknesses? How?; What new skills or knowledge can you learn to develop your strengths even more? Are there any books you can read, any courses you can take, any mentor you can follow? What are the first steps you need to take in order to do so?; What are the potential downsides of your strengths? In what contexts do you need to be particularly mindful of those?"). Participants were again invited to share their answers with their colleagues and to discuss about opportunities for better applying each other's strengths at work. The intervention program concluded with the facilitator thanking participants and encouraging them to keep discovering and using their strengths at work. Three months later, participants were again asked to complete the internet-based questionnaire (time 2) to report their levels on the same studied variables.

\section{Measures}

\section{Strengths Knowledge}

Strengths knowledge was measured using a French translation of the Strengths Knowledge Scale (Govindji and Linley 2007), which was obtained using a translation back translation procedure (Vallerand 1989) and also according to the guidelines of the International Test Commission (Hambleton 1993). This eight-item scale asked participants to indicate their agreement with sentences relating to the awareness of their own strengths (sample items: "I know my strengths well"; "I know the things I am good at doing") on a 1 (strongly disagree) to 7 (strongly agree) likert-type scale. Previous studies have shown a single-factor structure and adequate internal consistency levels $(\alpha=0.89)$ for this instrument (Govindji and Linley 2007). In the present study, the internal consistency levels were also satisfactory, with time $1 \alpha=0.75$ and time $2 \alpha=0.82$. 


\section{Strengths Use}

Strengths use was assessed using a French version of the Strengths Use Scale (Forest et al. 2012) originally developed by Govindji and Linley (2007). This 14-item instrument asked participants to rate their level of agreement with sentences relating to the use of their strengths (sample items: "Most of my time is spent doing the things I am good at doing"; "My work gives me lots of opportunities to use my strengths") on a 1 (strongly disagree) to 7 (strongly agree) likert-type scale. Previous studies have shown adequate internal consistency levels for this instrument, with $\alpha=0.96$ (Govindji and Linley 2007) and $\alpha=0.94-0.97$ (Wood et al. 2011), as well as a single-factor structure and appropriate test-retest stability (Wood et al. 2011). In the current study, the internal consistency levels were also satisfactory, with time $1 \alpha=0.95$ and time $2 \alpha=0.93$.

\section{Well-Being}

Well-being was measured using a French version of the Satisfaction With Life Scale (Blais et al. 1989), originally developed by Diener et al. (1985). This five-item instrument asked participants to rate their level of agreement with sentences relating to life satisfaction (sample items: "I am satisfied with my life"; "If I could live my life over, I would change almost nothing") on a 1 (strongly disagree) to 7 (strongly agree) likert-type scale. Previous studies revealed adequate internal consistency levels, with $\alpha=0.87$ (Diener et al. 1985), $\alpha=0.79-0.89$ (Pavot and Diener 1993), and $\alpha=0.88$ (Rousseau and Vallerand 2008), as well as a single-factor structure (Diener et al. 1985) and appropriate test-retest stability (Eid and Diener 2004; Pavot and Diener 1993). In the present study, the internal consistency levels for this instrument were also satisfactory, with time $1 \alpha=0.82$ and time $2 \alpha=0.80$.

\section{Work Performance}

Work performance was assessed using a French translation of the In-Role Behavior scale (Williams and Anderson 1991), which was obtained using a translation back translation procedure (Vallerand 1989) and also according to the guidelines of the International Test Commission (Hambleton 1993). This seven-item scale asked participants to rate their level of agreement with sentences relating to in-role performance behaviors (sample items: "I fulfill the responsibilities specified in my job description"; "I adequately complete my assigned duties") on a 1 (strongly disagree) to 7 (strongly agree) likert-type scale. Previous studies have indicated adequate internal consistency levels, with $\alpha=0.91$ (Williams and Anderson 1991) and $\alpha=0.95$ (Chung 2015), as well as a single-factor structure for this instrument (Williams and Anderson 1991). In the present study, the internal consistency levels were also satisfactory, with time 1 $\alpha=0.75$ and time $2 \alpha=0.70$.

\section{Harmonious Passion}

Harmonious passion at work was measured by the harmonious passion subscale of the passion toward work scale, originally developed in French by Vallerand and Houlfort (2003). This six-item subscale asked participants to indicate their level of agreement 
with sentences relating to harmonious passion at work (sample items: "My work is a passion, that I still manage to control"; "My work is in harmony with the other activities in my life") on a 1 (strongly disagree) to 7 (strongly agree) likert-type scale. Previous studies revealed a single factor structure and adequate internal consistency levels, with $\alpha=0.70-0.85$ (Vallerand and Houlfort 2003). The internal consistency levels were also satisfactory in the current study, with time $1 \alpha=0.84$ and time $2 \alpha=0.81$.

\section{Subjective Vitality}

Subjective vitality was assessed using a French version, which was adapted for work, of the subjective vitality scale (Rousseau 2002) originally developed by Ryan and Frederick (1997). This seven-item instrument asked participants to rate their level of agreement with sentences relating to subjective vitality (sample items: "At work, I feel alive and vital"; "At work, I have energy and spirit") on a 1 (strongly disagree) to 7 (strongly agree) likerttype scale. Previous studies have shown that the internal consistency coefficients levels for this instrument are adequate, with $\alpha=0.84-0.86$ (Ryan and Frederick 1997), $\alpha=0.85$ (Li 2010), and $\alpha=0.80-0.89$ (Bostic et al. 2000). Bostic et al. (2000) also confirmed the single factor structure of this scale. In the present study, the internal consistency levels were also satisfactory, with time $1 \alpha=0.86$ and time $2 \alpha=0.85$.

\section{Concentration}

Concentration was assessed using a French translation, which was adapted for work, of the concentration on task at hand subscale of the Flow State Scale (Forest et al. 2005) originally developed by Jackson and Marsh (1996). This three-item subscale asked participants to indicate their level of agreement with sentences relating to concentration at work (sample items: "My attention is entirely focused on what I am doing"; "I am completely focused on the task at hand") on a 1 (strongly disagree) to 7 (strongly agree) likert-type scale. Previous studies have shown that the internal consistency levels for this instrument are usually adequate, with $\alpha=0.82-0.87$ (Jackson and Marsh 1996), $\alpha=0.92$ (Forest et al. 2011), and $\alpha=0.89$ (Dubreuil et al. 2014). In the present study, the internal consistency levels were also satisfactory, with time 1 $\alpha=0.77$ and time $2 \alpha=0.82$.

\section{Results}

\section{Preliminary Analyses}

All analyses were performed using IBM SPSS Statistics 23.0. Missing values (maximum $3.6 \%$ ) were treated using the expectation maximization algorithm. Five participants were removed from the study because of univariate outliers, resulting in a final sample of 73 participants. All variables were normally distributed, with skewness values ranging from -0.94 to 0.50 and kurtosis values ranging from -0.86 to 1.00 (Kline 2011). Close inspection of the correlation matrix revealed no evidence of multicollinearity or singularity $(r>0.9)$. Means, standard deviations, correlations and alpha coefficients are reported in Table 1. 


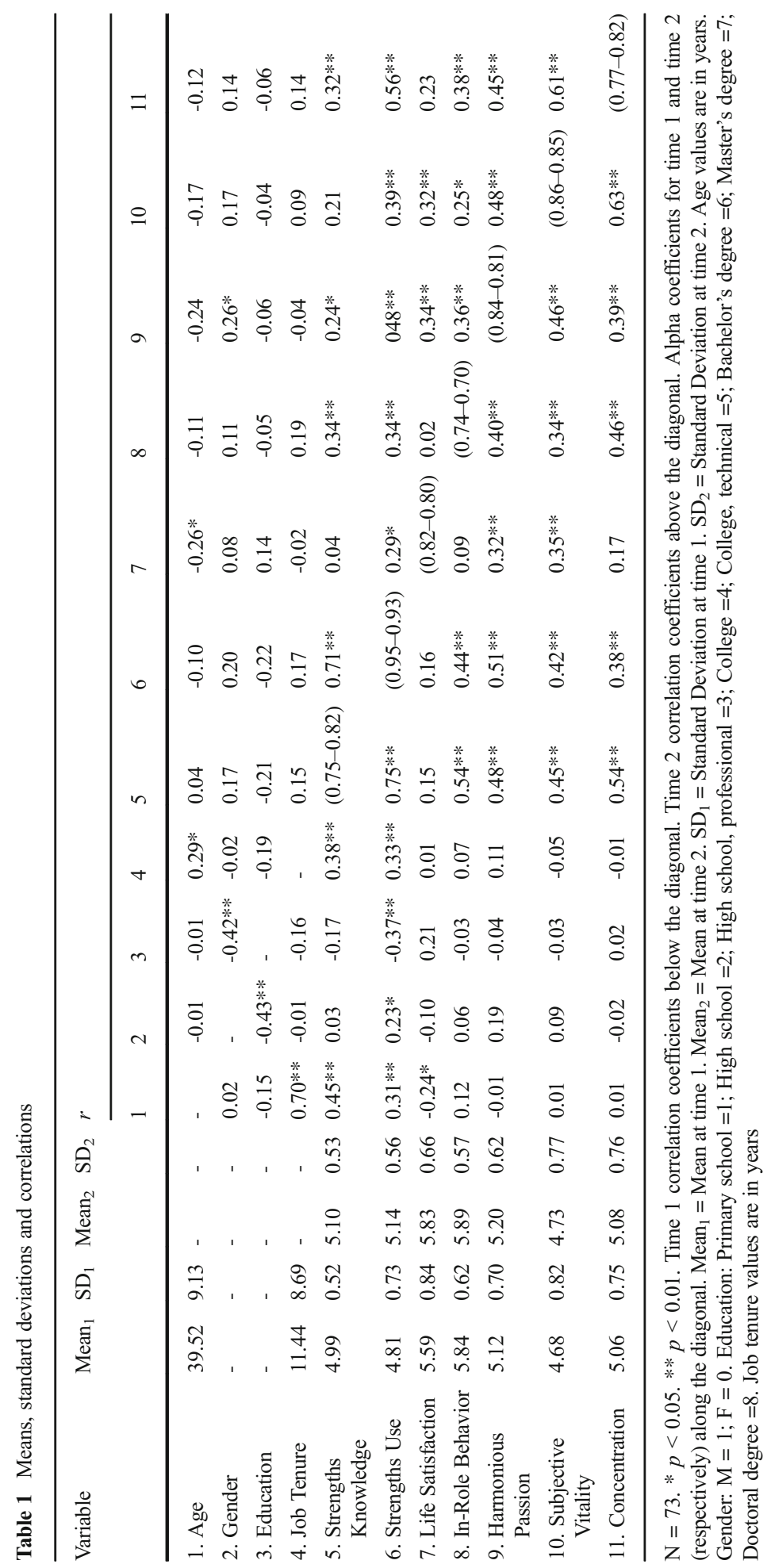


Table 2 Time 1 vs Time 2 paired sample $t$-tests

\begin{tabular}{lllllllll}
\hline Variable & T1 & T2 & Mean & SD & $t$ & $d f$ & $p$ & $95 \%$ CI \\
\hline Strengths Knowledge & 4.99 & 5.10 & 0.11 & 0.52 & 1.85 & 72 & 0.07 & {$[-0.01,0.23]$} \\
Strengths Use & 4.81 & 5.14 & 0.33 & 0.58 & 4.81 & 72 & 0.01 & {$[0.19,0.46]$} \\
Life Satisfaction & 5.59 & 5.83 & 0.24 & 0.73 & 2.85 & 72 & 0.01 & {$[0.08,0.41]$} \\
In-Role Behavior & 5.83 & 5.89 & 0.05 & 0.50 & 0.90 & 72 & 0.37 & {$[-0.06,0.17]$} \\
Harmonious Passion & 5.12 & 5.20 & 0.08 & 0.53 & 1.28 & 72 & 0.21 & {$[-0.04,0.20]$} \\
Subjective Vitality & 4.68 & 4.73 & 0.05 & 0.59 & 0.80 & 72 & 0.43 & {$[-0.08,0.19]$} \\
Concentration & 5.06 & 5.08 & 0.02 & 0.71 & 0.22 & 72 & 0.83 & {$[-0.15,0.17]$} \\
\hline
\end{tabular}

$\mathrm{T} 1=$ mean score at Time $1 . \mathrm{T} 2=$ mean score at Time 2. Mean $=$ mean difference between $\mathrm{T} 2$ and $\mathrm{T} 1$. $\mathrm{SD}=$ Standard Deviation

\section{Effects of the Intervention Program}

In order to verify the impact of the intervention program on the studied variables, a series of paired sample $t$-tests were conducted to compare the mean results at time 1 and time 2 (see Table 2). Results show a significant increase in strengths use and life satisfaction, but no difference for strengths knowledge, in-role behaviors, harmonious passion, subjective vitality and concentration. Although we were not able to compare these results to a control group, these results suggest that the intervention had an effect on the development of participants' strengths use and life satisfaction.

\section{Additional Analyses}

In light of these results, we decided to conduct further analyses in order to gain a deeper understanding of our data. More specifically, we were particularly interested in isolating different levels of change in strengths use following the intervention, and compare their effects on the studied variables.

The difference between results on strengths use at Time 1 and results on strengths use at Time 2 was calculated for each participant. Then, this variable was standardized using $\mathrm{z}$ scores and three groups were created. Participants in Group 1 (z scores lower than $-0.5, n=21)$ generally presented a decline in their strengths use from Time 1 to Time 2 $(M=-0.34, S D=0.06)$. Participants in Group 2 ( $\mathrm{z}$ scores between -0.5 and $0.5, n=29)$ showed an average increase in their strengths use from Time 1 to Time $2(M=0.29$, $S D=0.05$ ). Finally, participants in Group 3 (z scores higher than $0.5, n=23$ ) showed a high increase in their strengths use from Time 1 to Time $2(M=0.98, S D=0.06)$.

Repeated measures analyses with group as a between-subjects factor and intervention (Time 1 and Time 2) as a within-subject factor were conducted to determine whether the three groups differed significantly with respect to changes in harmonious passion, subjective vitality, concentration, and work performance from Time 1 to Time 2. For harmonious passion, results showed a significant group $\mathrm{x}$ intervention effect, $F(2,70)=17.06, p<0.001$. Post hoc pairwise comparisons (see Fig. 1) indicated that Group 1 showed a decrease $(p<0.01)$ from Time $1(M=5.55)$ to Time $2(M=5.24)$ in harmonious passion. Group 2 did not significantly differ $(p=0.53)$ between Time 1 


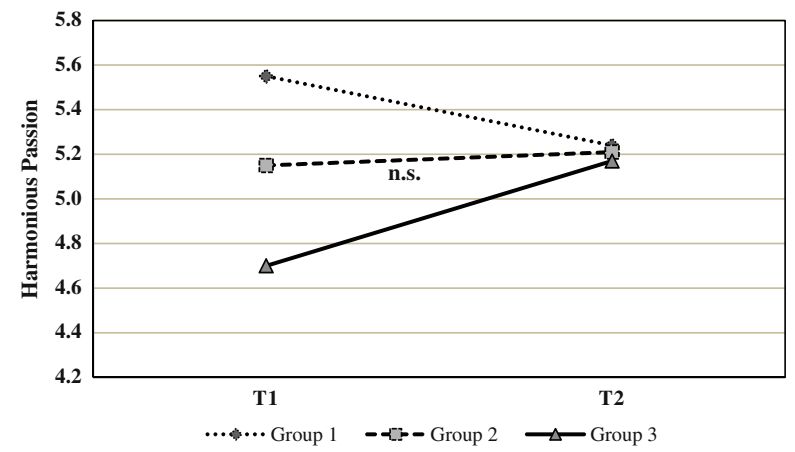

Fig. 1 Post-hoc pairwise comparisons on harmonious passion. $\mathrm{T} 1=$ mean score at Time $1 . \mathrm{T} 2=$ mean score at Time 2. n.s. = non-significant

$(M=5.15)$ and Time $2(M=5.21)$. Finally, Group 3 showed an increase $(p<0.001)$ from Time $1(M=4.70)$ to Time $2(M=5.17)$. For subjective vitality, $F(2,70)=0.77$, $p=0.47$, and concentration, $F(2,70)=1.88, p=0.16$, results showed a non-significant group $\mathrm{x}$ intervention effect. Finally, for in-role behaviors, results showed a significant group $\mathrm{x}$ intervention effect, $F(2,70)=3.24, p=0.04$. Post hoc pairwise comparisons (see Fig. 2) indicated that Group 1 did not significantly differ $(p=0.41)$ between Time $1(M=5.94)$ and Time $2(M=6.03)$. Likewise, Group 2 did not significantly differ $(p=0.22)$ between Time $1(M=5.94)$ and Time $2(M=5.83)$. Finally, Group 3 showed an increase $(p=0.03)$ from Time $1(M=5.61)$ to Time $2(M=5.84)$ regarding in-role behaviors.

\section{Discussion}

The objective of this study was to conceive a strengths development program and assess its impact on workers' strengths knowledge, strengths use, well-being, performance, harmonious passion, vitality and concentration.

Hypothesis 1 and 2 stated that the intervention program would increase participants' strengths knowledge (H1) and strengths use (H2). Although results did not reveal a significant increase in strengths knowledge, they indicated a significant increase in

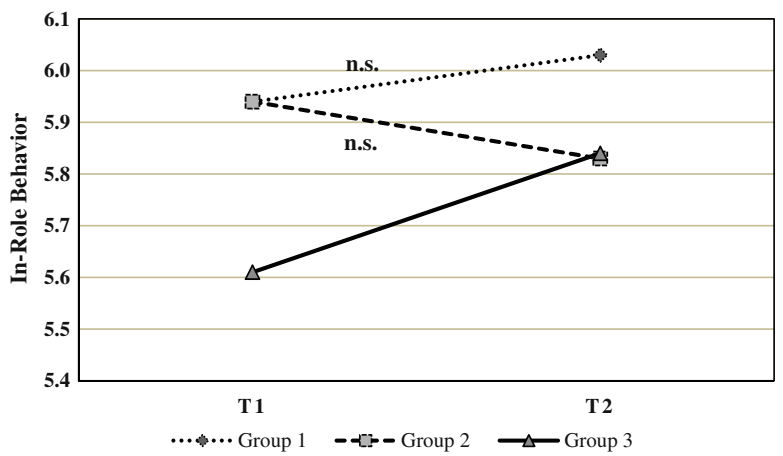

Fig. 2 Post-hoc pairwise comparisons on In-Role Behavior. T1 = mean score at Time 1 . T2 = mean score at Time 2. n.s. = non-significant 
strengths use between time 1 and time 2, thereby confirming hypothesis 2 . These results are interesting, because they suggest that the intervention program did not help participants gain a better awareness of their own strengths, but served them in increasing their daily use in the workplace. This could mean that the intervention program is mostly useful to stimulate participants to pay closer attention to their strengths and to find better ways to maximize their use. However, more studies are needed in order to clarify this question and replicate these findings.

Regarding the effects of the intervention program, hypothesis 3 and 4 stated that there would be an increase in participants' well-being (H3) and work performance (H4) after the intervention. Again, results revealed a significant increase in participants' wellbeing after the intervention, thereby confirming hypothesis 3 . These results are in line with numerous studies conducted on strengths development in various contexts (Gander et al. 2013; Mitchell et al. 2009; Mongrain and Anselmo-Matthews 2012; Proyer et al. 2015; Seligman et al. 2005) and corroborate the positive associations found between strengths use in the workplace and employee well-being (Forest et al. 2012; Harzer and Ruch 2012, 2013; Littman-Ovadia and Davidovitch 2010; Littman-Ovadia and Steger 2010). However, the results were inconclusive regarding hypothesis 4, as the change in participants' work performance between time 1 and time 2 was not significant. These results differ from reports from the field which indicate that strengths development generally fosters work performance (Asplund and Blacksmith 2012; Clifton and Harter 2003; Hodges and Asplund 2010; Hodges and Clifton 2004), as well as recent research showing positive associations between strengths use and work performance (Dubreuil et al. 2014; Harzer and Ruch 2014). These differences might be attributable to methodological issues, as the main instrument used in our intervention was the VIA Survey, whereas Hodges and Asplund (2010) and Clifton and Harter (2003) used the Clifton Strengthsfinder $\AA$. It is also possible that our intervention program differed from those used in previous research, given that no details could be found regarding the exact protocols followed (Asplund and Blacksmith 2012; Clifton and Harter 2003; Hodges and Asplund 2010; Hodges and Clifton 2004). Another possibility could be that participants did not receive sufficient assistance to ensure the transfer of training in their work environment after the intervention, as recent studies have shown that this is a critical step required to sustain the effects of strengths development programs in the mid to long term (Harzer and Ruch 2015; Meyers et al. 2015; Mongrain and Anselmo-Matthews 2012).

Regarding the psychological processes involved in strengths, hypothesis 5, 6 and 7 respectively stated that there would be an increase in harmonious passion, subjective vitality and concentration after the intervention. However, our results could not confirm these hypotheses, as the differences reported by participants on these variables between time 1 and time 2 were all non-significant. These results were surprising, as it was expected that strengths development would be logically accompanied by increases in harmonious passion (Dubreuil et al. 2014; Forest et al. 2012), vitality (Govindji and Linley 2007; Wood et al. 2011) and concentration (Buschor et al. 2013; Duckworth et al. 2005; Peterson et al. 2007).

On a broader perspective, a possible explanation of these results might be that in order to observe significant increases in work performance, harmonious passion, vitality and concentration, more time and effort must be devoted to help participants fully harness their strengths development opportunities following the intervention. Our 
results tend to support this possibility, since participants who benefited the most from the intervention program, that is, those who showed the highest increase in strengths use, not only reported gains in well-being, but also significant increases in harmonious passion and work performance. This seems to suggest that increases in strengths use do not automatically translate to increases in other variables such as harmonious passion and work performance, but rather after a certain threshold only. This could mean that strengths development interventions need particular time and personal investment to fully deliver their effects. This possibility therefore supports the idea that follow-up and knowledge transfer initiatives seem mandatory in order to maximize the effects of such interventions and facilitate the transfer of strengths training in tangible behavior changes and results. Again, more studies are needed in order to test and confirm this assumption.

\section{Limitations and Future Research Directions}

While this pilot study provides interesting results, it also presents some limitations. The main limitation concerns the absence of control group, which renders it impossible to isolate the effect of the intervention and infer any causality among the variables. Still, it remains a step in the right direction and we can reasonably believe from previous research that the intervention program is responsible for the observed changes (Buschor et al. 2013; Forest et al. 2012; Hodges and Asplund 2010; Mongrain and Anselmo-Matthews 2012; Wood et al. 2011). It also paves the way for the implementation of a larger scale research, in which a control group and more post-test measurement points (e.g., 1 month, 3 months and 6 months) would be added to confirm the effectiveness of the intervention program, better track changes in studied variables and allow for the measurement of long term effects. It would also be of interest to include other variables which could potentially explain how and under which conditions such programs are effective (e.g., individual factors such as need satisfaction and goal-setting type, contextual factors such as facilitator attitude, and environmental factors such as peer support, supervisor support and organizational culture; Quinlan et al. 2012). A second limitation concerns the fact that the intervention program was measured as a whole, which implies that it is impossible to dissociate and evaluate the respective contribution of each step of the intervention. Namely, we know from previous research that the mere identification of strengths, without any follow-up or development program, can induce an increase in well-being (Seligman et al. 2005). Future research should therefore also consider designs in which participants are divided in groups with different levels of intervention in order to allow for the comparison of their respective effects (e.g., Group 1: Strengths identification only; Group 2: Strengths identification and development program; Group 3: Strengths identification, development program and follow-up initiatives; Group 4: Control group). In that regard, we must stress again that it seems mandatory to include in future studies follow-up initiatives aimed at fostering participants' strengths use and development after the intervention (e.g., personal diary, meeting with supervisor, if-then plans, etc.). A third limitation concerns the use of self-reported assessments for all variables, which may introduce biases in the results, such as common-method-variance biases that tends to overestimate the size of the observed relations between variables (Podsakoff et al. 2012). In order to reduce these possible biases, future research should consider the inclusion of objective measurements, especially for work performance. Finally, a fourth limitation concerns the high proportion ( $93 \%$ ) of women present in our sample. This limitation was not a problem 
within the sample (as it is representative of the physical rehabilitation center's workforce), however it is not representative of the general population. More research is needed in order to replicate and validate these findings in a variety of populations and work sectors.

\section{Conclusion}

This pilot study provides innovative information for both researchers and professionals interested in strengths development. On a theoretical perspective, it is one of the first studies to propose and fully detail a strengths development program conducted in the workplace, and thoroughly assess its impact on key outcome variables such as strengths knowledge, strengths use, well-being, performance, harmonious passion, vitality and concentration. Although the effects of the intervention program were generally only conclusive regarding the development of strengths use and well-being, it remains interesting to note that participants who were able to make the most of the intervention program also reported significant increases in harmonious passion and work performance. These encouraging results suggest that future studies including follow-up exercises and a stronger design (i.e., control group and multiple measurement points) could be envisioned as a next step to this pilot research. On an applied perspective, this study also constitutes an important milestone, as it provides positive psychology and human resources professionals with a detailed intervention program that can be reproduced, tailored and conducted in a wide variety of organizations. On a broader level, it again encourages the identification, use and development of strengths in human management practices, demonstrating once more its potential regarding the improvement of employee well-being and work performance.

Acknowledgments Preparation of this article was facilitated through a grant from the Fonds de Recherche du Québec - Société et Culture to the first author and the research itself was facilitated by a grant from the Conseil de Recherche en Sciences Humaines du Canada to the second author.

\section{References}

Asplund, J., \& Blacksmith, N. (2012). Leveraging strengths. In K. S. Cameron \& G. M. Spreitzer (Eds.), The Oxford handbook of positive organizational scholarship (pp. 353-365). New York, NY: Oxford University Press.

Asplund, J., Lopez, S. J., Hodges, T., \& Harter, J. (2007). The Clifton strengths finder 2.0 technical report: development and validation. Princeton, NJ: Gallup Press.

Astakhova, M. N., \& Porter, G. (2015). Understanding the work passion-performance relationship: the mediating role of organizational identification and moderating role of fit at work. Human Relations, 68(8), 1315-1346. doi:10.1177/0018726714555204.

Bakker, A. B., Oerlemans, W., Demerouti, E., Slot, B., \& Ali, D. (2011). Flow and performance: a study among talented Dutch soccer players. Psychology of Sport and Exercise, 12(4), 442-450. doi:10.1016/j. psychsport.2011.02.003.

Biswas-Diener, R. (2010). Practicing positive psychology coaching: assessment, activities, and strategies for success. Hoboken, NJ: John Wiley \& Sons Inc.. doi:10.1002/9781118269633.

Biswas-Diener, R., Linley, P. A., Govindji, R., \& Woolston, L. (2011a). Positive psychology as a force for social change. In K. M. Sheldon, T. B. Kashdan, \& M. F. Steger (Eds.), Designing positive psychology: taking stock and moving forward (pp. 410-418). New York, NY: Oxford University Press. doi:10.1093 /acprof:oso/9780195373585.003.0027. 
Biswas-Diener, R., Kashdan, T. B., \& Minhas, G. (2011b). A dynamic approach to psychological strength development and intervention. The Journal of Positive Psychology, 6(2), 106-118. doi:10.1080 $/ 17439760.2010 .545429$.

Blais, M. R., Vallerand, R. J., Pelletier, L. G., \& Brière, N. M. (1989). L'échelle de satisfaction de vie: validation canadienne-française du 'satisfaction with life scale.' = The satisfaction scale: Canadian-French validation of the satisfaction with life scale. Canadian Journal of Behavioural Science/Revue Canadienne des Sciences du Comportement, 21(2), 210-223. doi:10.1037/h0079854.

Bonneville-Roussy, A., Lavigne, G. L., \& Vallerand, R. J. (2011). When passion leads to excellence: the case of musicians. Psychology of Music, 39(1), 123-138. doi:10.1177/0305735609352441.

Bostic, T. J., Rubio, D. M., \& Hood, M. (2000). A validation of the subjective vitality scale using structural equation modeling. Social Indicators Research, 52(3), 313-324. doi:10.1023/A:1007136110218.

Buckingham, M. (2007). Go put your strengths to work. New York, NY: Free Press.

Buschor, C., Proyer, R. T., \& Ruch, W. (2013). Self- and peer-rated character strengths: how do they relate to satisfaction with life and orientations to happiness? The Journal of Positive Psychology, 8(2), 116-127. doi:10.1080/17439760.2012.758305.

Cameron, K. S., Dutton, J. E., \& Quinn, R. E. (2003). Positive organizational scholarship: foundations of a new discipline. San Francisco, CA: Berrett-Koehler Publishers.

Carmeli, A., Ben-Hador, B., Waldman, D. A., \& Rupp, D. E. (2009). How leaders cultivate social capital and nurture employee vigor: implications for job performance. The Journal of Applied Psychology, 94(6), 1553-1561. doi:10.1037/a0016429.

Chung, Y. W. (2015). The mediating effects of organizational conflict on the relationships between workplace ostracism with in-role behavior and organizational citizenship behavior. International Journal of Conflict Management, 26(4), 366-385. doi:10.1108/IJCMA-01-2014-0001.

Clifton, D., \& Harter, J. K. (2003). Investing in strengths. In K. S. Cameron, J. Dutton, \& R. Quinn (Eds.), Positive organizational scholarship (pp. 111-121). San Francisco, CA: Berrett-Koehler Publishers.

Csikszentmihalyi, M., \& Csikzsentmihalyi, I. (2006). A life worth living: contributions to positive psychology. New York, NY: Oxford University Press.

Csikszentmihalyi, M., \& Nakamura, J. (2011). Positive psychology: where did it come from, where is it going? In K. M. Sheldon, T. B. Kashdan, \& M. F. Steger (Eds.), Designing positive psychology: taking stock and moving forward (pp. 3-8). New York, NY: Oxford University Press. doi:10.1093 /acprof:oso/9780195373585.003.0001.

Dahlsgaard, K., Peterson, C., \& Seligman, M. P. (2005). Shared virtue: the convergence of valued human strengths across culture and history. Review of General Psychology, 9(3), 203-213. doi:10.1037/10892680.9.3.203.

Demerouti, E. (2006). Job characteristics, flow, and performance: the moderating role of conscientiousness. Journal of Occupational Health Psychology, 11(3), 266-280. doi:10.1037/1076-8998.11.3.266.

Diener, E., Emmons, R. A., Larsen, R. J., \& Griffin, S. (1985). The satisfaction with life scale. Journal of Personality Assessment, 49(1), 71-75. doi:10.1207/s15327752jpa4901_13.

Duan, W., Ho, S. Y., Tang, X., Li, T., \& Zhang, Y. (2014). Character strength-based intervention to promote satisfaction with life in the Chinese university context. Journal of Happiness Studies, 15(6), 1347-1361. doi:10.1007/s10902-013-9479-y.

Dubreuil, P., Forest, J., \& Courcy, F. (2014). From strengths use to work performance: the role of harmonious passion, subjective vitality, and concentration. The Journal of Positive Psychology, 9(4), 335-349. doi:10.1080/17439760.2014.898318.

Duckworth, A., Steen, T. A., \& Seligman, M. P. (2005). Positive psychology in clinical practice. Annual Review of Clinical Psychology, 1(1), 629-651. doi:10.1146/annurev.clinpsy.1.102803.144154.

Eid, M., \& Diener, E. (2004). Global judgments of subjective well-being: situational variability and long-term stability. Social Indicators Research, 65(3), 245-277. doi:10.1023/B:SOCI.0000003801.89195.bc.

Eisenberger, R., Jones, J. R., Stinglhamber, F., Shanock, L., \& Randall, A. T. (2005). Flow experiences at work: for high need achievers alone? Journal of Organizational Behavior, 26(7), 755-775. doi:10.1002/job.337.

Engeser, S., \& Rheinberg, F. (2008). Flow, performance and moderators of challenge-skill balance. Motivation and Emotion, 32(3), 158-172. doi:10.1007/s11031-008-9102-4.

Forest, J., LeBrock, P., Madore, I., \& Boudrias, J.-S. (2005). Comment mesurer le plaisir au travail? [How to measure pleasure at work?] Proceedings of the 13th congress of the Association Internationale de Psychologie du Travail de Langue Française (pp. 707-716). Bologna, Italia: CLUEB.

Forest, J., Mageau, G. A., Sarrazin, C., \& Morin, E. (2011). « work is my passion »: the different affective, behavioural, and cognitive consequences of harmonious and obsessive passion toward work. Canadian Journal of Administrative Sciences, 28, 27-40. doi:10.1002/cjas.170. 
Forest, J., Mageau, G. A., Crevier-Braud, L., Bergeron, É., Dubreuil, P., \& Lavigne, G. L. (2012). Harmonious passion as an explanation of the relation between signature strengths' use and well-being at work: test of an intervention program. Human Relations, 65(9), 1233-1252. doi:10.1177/0018726711433134.

Fritz, B. S., \& Avsec, A. (2007). The experience of flow and subjective well-being of music students. Psihološka Obzorja / Horizons of Psychology, 16(2), 5-17.

Gander, F., Proyer, R. T., Ruch, W., \& Wyss, T. (2013). Strength-based positive interventions: further evidence for their potential in enhancing well-being and alleviating depression. Journal of Happiness Studies, 14(4), 1241-1259. doi:10.1007/s10902-012-9380-0.

Govindji, R., \& Linley, A. (2007). Strengths use, self-concordance and well-being: implications for strengths coaching and coaching psychologists. International Coaching Psychology Review, 2(2), 143-153.

Hambleton, R. K. (1993). Translating achievement tests for use in cross-national studies. European Journal of Psychological Assessment, 9(1), 57-68.

Harzer, C., \& Ruch, W. (2012). When the job is a calling: the role of applying one's signature strengths at work. The Journal of Positive Psychology, 7(5), 362-371. doi:10.1080/17439760.2012.702784.

Harzer, C., \& Ruch, W. (2013). The application of signature character strengths and positive experiences at work. Journal of Happiness Studies, 14(3), 965-983. doi:10.1007/s10902-012-9364-0.

Harzer, C., \& Ruch, W. (2014). The role of character strengths for task performance, job dedication, interpersonal facilitation, and organizational support. Human Performance, 27(3), 183-205. doi:10.1080/08959285.2014.913592.

Harzer, C., \& Ruch, W. (2015). Your strengths are calling: preliminary results of a web-based strengths intervention to increase calling. Journal of Happiness Studies. doi:10.1007/s10902-015-9692-y.

Ho, V. T., Wong, S., \& Lee, C. (2011). A tale of passion: linking job passion and cognitive engagement to employee work performance. Journal of Management Studies, 48(1), 26-47. doi:10.1111/j.14676486.2009.00878.x.

Hodges, T. D., \& Asplund, J. (2010). Strengths development in the workplace. In P. Linley, S. Harrington, \& N. Garcea (Eds.), Oxford handbook of positive psychology and work (pp. 213-220). New York, NY: Oxford University Press.

Hodges, T. D., \& Clifton, D. O. (2004). Strengths-based development in practice. In P. Linley \& S. Joseph (Eds.), Positive psychology in practice (pp. 256-268). Hoboken, NJ US: John Wiley \& Sons Inc..

Jackson, S. A., \& Marsh, H. W. (1996). Development and validation of a scale to measure optimal experience: the flow state scale. Journal of Sport \& Exercise Psychology, 18(1), 17-35.

Kaiser, R. B., \& Overfield, D. V. (2011). Strengths, strengths overused, and lopsided leadership. Consulting Psychology Journal: Practice and Research, 63(2), 89-109. doi:10.1037/a0024470.

Kashdan, T. B., \& Steger, M. F. (2011). Challenges, pitfalls, and aspirations for positive psychology. In K. M. Sheldon, T. B. Kashdan, \& M. F. Steger (Eds.), Designing positive psychology: taking stock and moving forward (pp. 9-21). New York, NY: Oxford University Press. doi:10.1093 /acprof:oso/9780195373585.003.0002.

Kawabata, M., \& Mallett, C. J. (2011). Flow experience in physical activity: examination of the internal structure of flow from a process-related perspective. Motivation and Emotion, 35(4), 393-402. doi:10.1007/s11031-011-9221-1.

Kline, R. B. (2011). Principles and practice of structural equation modeling. New York, NY: Guilford Press.

Koch, S., \& Leary, D. E. (1985). A century of psychology as science. New York, NY: McGraw-Hill.

Kong, D. J., \& Ho, V. (2015). A self-determination perspective on strengths use at work. The Journal of Positive Psychology, 1-11. doi:10.1080/17439760.2015.1004555.

Kuo, T., \& Ho, L. (2010). Individual difference and job performance: the relationships among personal factors, job characteristics, flow experience, and service quality. Social Behavior and Personality, 38(4), 531-552. doi:10.2224/sbp.2010.38.4.531.

Lavigne, G. L., Forest, J., \& Crevier-Braud, L. (2012). Passion at work and burnout: a two-study test of the mediating role of flow experiences. European Journal of Work and Organizational Psychology, 21(4), 518-546. doi:10.1080/1359432X.2011.578390.

Li, C. (2010). Predicting subjective vitality and performance in sports: the role of passion and achievement goals. Perceptual and Motor Skills, 110(3, Pt 2), 1029-1047. doi:10.2466/05.06.07.14.PMS.110.C.1029-1047.

Linley, P. A. (2008). Average to a+: Realising strengths in yourself and others. Coventry, UK: CAPP Press.

Linley, P.A. (2009). Technical manual and statistical properties of Realise2. Coventry: Centre of Applied Positive Psychology. Available from www.cappeu.com/realise2.htm

Linley, P. A., \& Harrington, S. (2006). Playing to your strengths. The Psychologist, 19(2), 86-89.

Linley, P. A., \& Joseph, S. (2004). Positive psychology in practice. Hoboken, NJ: John Wiley \& Sons Inc..

Linley, P. A., Joseph, S., Harrington, S., \& Wood, A. M. (2006). Positive psychology: past, present, and (possible) future. The Journal of Positive Psychology, 1(1), 3-16. doi:10.1080/17439760500372796. 
Linley, A., Willars, J., \& Biswas-Diener, R. (2010a). The strengths book. Coventry, UK: CAPP Press.

Linley, P. A., Harrington, S., \& Garcea, N. (2010b). Oxford handbook of positive psychology and work. New York, NY: Oxford University Press.

Linley, P. A., Garcea, N., Harrington, S., Trenier, E., \& Minhas, G. (2011). Organizational applications of positive psychology: taking stock and a research/practice roadmap for the future. In K. M. Sheldon, T. B. Kashdan, \& M. F. Steger (Eds.), Designing positive psychology: taking stock and moving forward (pp. 365-381). New York, NY: Oxford University Press. doi:10.1093/acprof:oso/9780195373585.003.0024.

Littman-Ovadia, H., \& Davidovitch, N. (2010). Effects of congruence and character-strength deployment on work adjustment and well-being. International Journal of Business and Social Science, 1(3), 138-146.

Littman-Ovadia, H., \& Steger, M. (2010). Character strengths and well-being among volunteers and employees: toward an integrative model. The Journal of Positive Psychology, 5(6), 419-430. doi:10.1080 $/ 17439760.2010 .516765$.

Lopez, S. J., \& Snyder, C. R. (2009). Oxford handbook of positive psychology. New York, NY: Oxford University Press.

Meyers, M. C., van Woerkom, M., de Reuver, R. M., Bakk, Z., \& Oberski, D. L. (2015). Enhancing psychological capital and personal growth initiative: working on strengths or deficiencies. Journal of Counseling Psychology, 62(1), 50-62. doi:10.1037/cou0000050.

Mitchell, J., Stanimirovic, R., Klein, B., \& Vella-Brodrick, D. (2009). A randomised controlled trial of a selfguided internet intervention promoting well-being. Computers in Human Behavior, 25(3), 749-760. doi:10.1016/j.chb.2009.02.003.

Mongrain, M., \& Anselmo-Matthews, T. (2012). Do positive psychology exercises work? A replication of Seligman et al. (2005). Journal of Clinical Psychology, 68(4), 382-389. doi:10.1002/jclp.21839.

Nakamura, J., \& Csikszentmihalyi, M. (2002). The concept of flow. In C. R. Snyder \& S. J. Lopez (Eds.), Handbook of positive psychology (pp. 89-105). New York, NY: Oxford University Press.

Park, N., \& Peterson, C. (2008). Positive psychology and character strengths: application to strengths-based school counseling. Professional School Counseling, 12(2), 85-92. doi:10.5330/PSC.n.2010-12.85.

Park, N., Peterson, C., \& Seligman, M. P. (2004). Strengths of character and well-being. Journal of Social and Clinical Psychology, 23(5), 603-619. doi:10.1521/jscp.23.5.603.50748.

Pavot, W., \& Diener, E. (1993). Review of the satisfaction with life scale. Psychological Assessment, 5(2), 164-172. doi:10.1037/1040-3590.5.2.164.

Peterson, C., \& Park, N. (2006). Character strengths in organizations. Journal of Organizational Behavior, 27(8), 1149-1154. doi:10.1002/job.398.

Peterson, C., \& Seligman, M. E. P. (2004). Character strengths and virtues: a handbook and classification. Washington D.C., US: American Psychological Association.

Peterson, C., Ruch, W., Beermann, U., Park, N., \& Seligman, M. P. (2007). Strengths of character, orientations to happiness, and life satisfaction. The Journal of Positive Psychology, 2(3), 149-156. doi:10.1080 /17439760701228938.

Peterson, C., Stephens, J. P., Park, N., Lee, F., \& Seligman, M. E. P. (2010). Strengths of character and work. In A. Linley, S. Harrington, \& N. Garcea (Eds.), Oxford handbook of positive psychology and work (pp. 221-231). New York, NY: Oxford University Press.

Philippe, F. L., Vallerand, R. J., \& Lavigne, G. L. (2009). Passion does make a difference in people's lives: a look at well-being in passionate and non-passionate individuals. Applied Psychology. Health and WellBeing, 1(1), 3-22.

Podsakoff, P. M., MacKenzie, S. B., \& Podsakoff, N. P. (2012). Sources of method bias in social science research and recommendations on how to control it. Annual Review of Psychology, 63, 539-569. doi:10.1146/annurev-psych-120710-100452.

Proctor, C., Tsukayama, E., Wood, A. M., Maltby, J., Eades, J., \& Linley, P. (2011). Strengths gym: the impact of a character strengths-based intervention on the life satisfaction and well-being of adolescents. The Journal of Positive Psychology, 6(5), 377-388. doi:10.1080/17439760.2011.594079.

Proyer, R. T., Gander, F., Wellenzohn, S., \& Ruch, W. (2015). Strengths-based positive psychology interventions: a randomized placebo-controlled online trial on long-term effects for a signature strengths- vs. a lesser strengths- intervention. Frontiers in Psychology, 6, 456. doi:10.3389/fpsyg.2015.00456.

Quinlan, D., Swain, N., \& Vella-Brodrick, D. A. (2012). Character strengths interventions: building on what we know for improved outcomes. Journal of Happiness Studies, 13(6), 1145-1163. doi:10.1007/s10902-011-9311-5.

Quinlan, D. M., Swain, N., Cameron, C., \& Vella-Brodrick, D. A. (2015). How 'other people matter' in a classroom-based strengths intervention: exploring interpersonal strategies and classroom outcomes. The Journal of Positive Psychology, 10(1), 77-89. doi:10.1080/17439760.2014.920407.

Rashid, T. (2015). Positive psychotherapy: a strength-based approach. The Journal of Positive Psychology, 10(1), 25-40. doi:10.1080/17439760.2014.920411. 
Rousseau, F. L. (2002). Passion, affect et bien-être subjectif chez les aînés [Passion, affect and subjective wellbeing in older adults] (Unpublished doctoral thesis). Montreal: Université du Québec à Montréal.

Rousseau, F. L., \& Vallerand, R. J. (2008). An examination of the relationship between passion and subjective well-being in older adults. The International Journal of Aging and Human Development, 66(3), 195-211. doi:10.2190/AG.66.3.b.

Rust, T., Diessner, R., \& Reade, L. (2009). Strengths only or strengths and relative weaknesses? A preliminary study. Journal of Psychology: Interdisciplinary and Applied, 143(5), 465-476. doi:10.3200 /JRL.143.5.465-476.

Ryan, R. M., \& Frederick, C. (1997). On energy, personality, and health: subjective vitality as a dynamic reflection of well-being. Journal of Personality, 65(3), 529-565. doi:10.1111/j.1467-6494.1997.tb00326.x.

Salanova, M., Agut, S., \& Peiró, J. (2005). Linking organizational resources and work engagement to employee performance and customer loyalty: the mediation of service climate. The Journal of Applied Psychology, 90(6), 1217-1227. doi:10.1037/0021-9010.90.6.1217.

Schuler, J., \& Brunner, S. (2009). The rewarding effect of flow experience on performance in a marathon race. Psychology of Sport and Exercise, 10(1), 168-174. doi:10.1016/j.psychsport.2008.07.001.

Seligman, M. P., \& Csikszentmihalyi, M. (2000). Positive psychology: an introduction. The American Psychologist, 55(1), 5-14. doi:10.1037/0003-066X.55.1.5.

Seligman, M. P., Steen, T. A., Park, N., \& Peterson, C. (2005). Positive psychology progress: empirical validation of interventions. The American Psychologist, 60(5), 410-421. doi:10.1037/0003-066 X.60.5.410.

Seligman, M. P., Ernst, R. M., Gillham, J., Reivich, K., \& Linkins, M. (2009). Positive education: positive psychology and classroom interventions. Oxford Review of Education, 35(3), 293-311. doi:10.1080 /03054980902934563.

Snyder, C. R., \& Lopez, S. J. (2002). Handbook of positive psychology. New York, NY: Oxford University Press. Spreitzer, G. M., \& Cameron, K. C. (2012). Conclusion. In K. S. Cameron \& G. M. Spreitzer (Eds.), The Oxford handbook of positive organizational scholarship (pp. 1034-1048). New York, NY: Oxford University Press.

Stavrou, N. A., Jackson, S. A., Zervas, Y., \& Karteroliotis, K. (2007). Flow experience and athletes' performance with reference to the orthogonal model of flow. The Sport Psychologist, 21(4), 438-457.

Straume, L. V. (2008). Flow as a resource: A contribution to organizational psychology (Unpublished doctoral thesis). Trondheim: Norwegian University of Science and Technology.

Tabachnick, B. G., \& Fidell, L. F. (2007). Using multivariate statistics. Boston, MA: Pearson.

Vallerand, R. J. (1989). Vers une méthodologie de validation trans-culturelle de questionnaires psychologiques: implications pour la recherche en langue française [Towards a methodology for transcultural validation of psychological questionnaires: implications for French language research]. Canadian Psychology/Psychologie Canadienne, 30(4), 662-680. doi:10.1037/h0079856.

Vallerand, R. J., \& Houlfort, N. (2003). Passion at work: toward a new conceptualization. In W. Gilliand, D. D. Steiner, \& D. P. Skalicki (Eds.), Emerging perspectives on values in organizations (pp. 175-204). New York, NY: Information Age Publishing.

Vallerand, R. J., Salvy, S., Mageau, G. A., Elliot, A. J., Denis, P. L., Grouzet, F. E., \& Blanchard, C. (2007). On the role of passion in performance. Journal of Personality, 75(3), 505-534. doi:10.1111/j.14676494.2007.00447.x.

Vallerand, R. J., Mageau, G. A., Elliot, A. J., Dumais, A., Demers, M., \& Rousseau, F. (2008). Passion and performance attainment in sport. Psychology of Sport and Exercise, 9(3), 373-392. doi:10.1016/j. psychsport.2007.05.003.

Vallerand, R. J., Houlfort, N., \& Forest, J. (2014). Passion for work: determinants and outcomes. In M. Gagné (Ed.), The Oxford handbook of work engagement, motivation, and self-determination theory (pp. 85105). Oxford, UK: Oxford University Press.

Wanner, B., Ladouceur, R., Auclair, A. V., \& Vitaro, F. (2006). Flow and dissociation: examination of mean levels, cross-links, and links to emotional well-being across sports and recreational and pathological gambling. Journal of Gambling Studies, 22(3), 289-304. doi:10.1007/s10899-006-9017-5.

Williams, L. J., \& Anderson, S. E. (1991). Job satisfaction and organizational commitment as predictors of organizational citizenship and in-role behaviors. Journal of Management, 17(3), 601-617. doi:10.1177 /014920639101700305.

Wood, A. M., Linley, P., Maltby, J., Kashdan, T. B., \& Hurling, R. (2011). Using personal and psychological strengths leads to increases in well-being over time: a longitudinal study and the development of the strengths use questionnaire. Personality and Individual Differences, 50(1), 15-19. doi:10.1016/j. paid.2010.08.004. 